\title{
Kidney Soft Tissue Tumors
}

The following is the list of soft tissue tumors of the kidney according the WHO Classification published in 2016.

For details on each single tumor, $\rightarrow$ see dedicated sections.

\begin{tabular}{l|l}
\hline Tumor & Notes \\
\hline Angiomyolipoma & - \\
\hline Angiosarcoma & - \\
\hline $\begin{array}{l}\text { Congenital mesoblastic } \\
\text { nephroma }\end{array}$ & Occurring mainly in children \\
\hline Epithelioid angiomyolipoma & $\rightarrow$ See Chap. 24 \\
\hline Ewing sarcoma & $\rightarrow$ See Chap. 93 \\
\hline Hemangioblastoma & - \\
\hline Hemangioma & - \\
\hline Juxtaglomerular cell tumor & - \\
\hline Kidney clear cell sarcoma & $\begin{array}{l}\text { Occurring mainly in children; also known as clear cell sarcoma } \\
\text { of the kidney }\end{array}$ \\
\hline Kidney rhabdoid tumor & $\begin{array}{l}\text { Occurring mainly in children; also known as rhabdoid tumor of } \\
\text { the kidney }\end{array}$ \\
\hline Leiomyoma & - \\
\hline Leiomyosarcoma & - \\
\hline Lymphangioma & - \\
\hline Osteosarcoma & $\rightarrow$ See Chap. 95 \\
\hline Rhabdomyosarcoma & - \\
\hline Schwannoma & - \\
\hline Solitary fibrous tumor & - \\
\hline Synovial sarcoma & -
\end{tabular}

